\title{
Metilen Mavisinin SiCl@AgNP Nanokompoziti ile Gideriminin İncelenmesi
}

\author{
Bülent KIRKAN ${ }^{* 1}$, Burcu Akyol ORAL ${ }^{2}$ \\ ${ }^{1}$ Süleyman Demirel Üniversitesi, Su Enstitüsü, 32000, Isparta, Türkiye \\ ${ }^{2}$ Süleyman Demirel Üniversitesi, Fen Bilimleri Enstitüsü, Su Yönetimi Anabilim Dalı, 32000, Isparta, Türkiye
}

(Alınış / Received: 18.05.2021, Kabul / Accepted: 05.08.2021, Online Yayınlanma / Published Online: 25.12.2021)

Anahtar Kelimeler

Biyosentez,

Defne yaprağl,

AgNP,

Nanokompozit,

Metilen mavisi,

Giderim
Özet: Bu çalışmada; defne yaprağı (Laurus nobilis) su özütü kullanılarak biyosentez yöntemi ile SiCl@AgNP nanokompozit sentezlenmiştir. Üretilmiş olan nanokompozitin yapısı UV-Vis., FTIR, XRD ve SEM teknikleri ile karakterize edilmiștir. Daha sonra üretilmiș olan nanokompozit adsorbent, sulu çözeltiden bir katyonik boyar madde olan metilen mavisinin (MM) gideriminde değerlendirilmiştir. İlk olarak adsorpsiyon sürecine etki edebilecek parametrelerden, çözelti $\mathrm{pH}^{\prime} ı$, başlangıç $\mathrm{MM}$ konsantrasyonu, temas süresi, adsorbent dozu ve ortam sıcaklığının etkisi incelenmiștir. Deneysel verilerin Langmuir, Freundlich ve D-R izotermlerine uygunluğu analiz edilmiş ve Langmuir izoterm modeli ile uyum sağladığı gözlemlenmiştir. Gibbs serbest enerjisi, entropi ve entalpi değişikliği termodinamik parametreleri hesaplanmış ve elde edilen değerler MM adsorpsiyonunun uygulanabilirliğini ve endotermik karakterli olduğunu göstermiştir. Biyosentez yöntemi ile üretilmiş olan düşük maliyetli SiCl@AgNP nanokompozitinin sulu çözeltiden MM boyar madde gideriminde etkili bir adsorbent olduğu belirlenmiştir. Ayrıca üretilmiş olan nanokompozit adsorbentin diğer katyonik boyar maddelerin gideriminde de kullanılabileceği önerilmiştir.

\section{Investigation of the Removal of Methylene Blue with SiCl@AgNP Nanocomposite}

\section{Keywords}

Biosynthesis,

Leave of daphne,

AgNP,

Nanocompozit, Methylene blue, Removal

\begin{abstract}
In this study; SiCl@AgNP nanocomposite was synthesized by biosynthesis method using water extract of bay leaf (Laurus nobilis). The structure of the produced nanocomposite was characterized by UV-Vis., FTIR, XRD and SEM techniques. Then, the produced nanocomposite adsorbent was evaluated in the removal of methylene blue (MM), which is a cationic dye, from the aqueous solution. First, the effects of solution $\mathrm{pH}$, initial MM concentration, contact time, adsorbent dose and ambient temperature were investigated among the parameters that may affect the adsorption process. The suitability of the experimental data to the Langmuir, Freundlich and D-R isotherms was analyzed and it was observed that it was compatible with the Langmuir isotherm model. Thermodynamic parameters of Gibbs free energy, entropy and enthalpy change were calculated and the values obtained showed the applicability of MM adsorption and its endothermic character. It has been determined that low-cost SiCl@AgNP nanocomposite produced by biosynthesis method is an effective adsorbent in MM dyestuff removal from aqueous solution. In addition, it has been suggested that the produced nanocomposite adsorbent can be used in the removal of other cationic dyestuffs.
\end{abstract}

\section{Giriş}

Su kaynaklarının kirlenmesi sonucunda oluşacak olumsuz etkiler sadece temiz su talebini sinırlandırmakla kalmayıp sucul ortamda mevcut canlı ekolojisinin de olumsuz etkilenmesine sebep olmaktadır. Dünya üzerinde mevcut su kaynaklarının kirlenmesi sonucunda kullanılamaz duruma gelmesi geleceğe yönelik büyük problemlerin meydana gelmesine neden olacaktır. Su kirliliği kaynakları; nüfus artışı, şehirleşme, sanayileşme ve tarımsal uygulamalar olmak üzere dört ana başlık altında toplanabilir. Sanayileşmenin artışı ile kullanılan kimyasallar, kontrolsüz deşarj, kapsamlı gerçekleştirilemeyen arıtım sonucunda geri dönüşü mümkün olmayan çevresel sorunlara neden olmaktadır. Özellikle gerçekleştirilen endüstriyel faaliyetler sonucunda meydana gelen kirlilik 
kaynakları toksik ağır metaller ve boyar maddelerdir. Boyar maddelerin kullanımının yaygın olduğu endüstrilerin başlıcaları plastik, kozmetik, deri ve tekstil sektörleridir. Söz konusu sektörlerde boyar madde kullanımının artışı sonucunda atık suyun renk yüküde artış göstermektedir. Su kaynaklarında mevcut farklı kirleticiler sucul ekolojide bulunan çanlılarda biyo birikimi sonucunda besin zinciri ile insanlara ulaşmasıyla toksik ve kanserojen etkilere sebep olabilmektedir. Bu nedenle araştırmacılar için bu alanda su kirliliği giderimine yönelik farklı yöntemler üzerine çalışmalara ilgi günümüzde artış göstermektedir.

Katyonik karakterli boyar madde olan metilen mavisi, su kaynakların kirlenmesinde karşımıza çıkmaktadır. Metilen mavisi molekül kütlesi 373,9 gram ve kapalı formülü ise $\mathrm{C}_{16} \mathrm{H}_{18} \mathrm{~N}_{3} \mathrm{SCI} .3 \mathrm{H}_{2} \mathrm{O}^{\prime}$ dır. Renk yoğunluğunun fazla olması nedeniyle çok az miktarı bile yoğun renk içeriğine sahip olabilen bir boyar maddedir.

Metalik nanopartikül yapıları kullanım alanlarına göre kendi başlarına ihtiyaca karşılık verememeleri durumunda çekirdek-kabuk (core-shell) yapıya sahip olan nanokompozitler üretilmektedir. Nano yapıya sahip malzemeler, yeni sentez teknikleri kullanılarak ihtiyaca göre talep edilen şekil (çubuk, silindir, kübik vb.) ve özelliklere sahip olarak üretilebilmektedir. Gümüş, nikel, platin, bakır vb. metalik nanopartiküller silika çekirdeğe modifiye edilerek çekirdek-kabuk yapıya sahip nanokompozitler üretilebilmektedir [1].

Biyosentez yöntemi ile üretilmiş olan AgNPs metalik nanopartikül ve nanokompozit malzemelerin teknoloji ve bilimin farklı alanlarında çok geniş kapsamlı olarak farklı uygulama alanlarına sahiptir. $\mathrm{Bu}$ uygulama alanları arasında çevresel uygulamalar açısından önderiştirme[2] ve giderim süreçlerinde adsorbent olarak yaygın kullanıma sahiptir [3-9]. Literatürde farklı bitki özütleri [5-12] kullanılarak biyosentez yöntemi ile AgNP nanopartikül üretimi çalışmaları bulunmaktadır. Fakat bir indirgeyici ajan olarak defne yaprağı (Laurus nobilis) özütü kullanılarak SiCl@AgNP nanokompozit üretimine ait bir çalışma literatürde bulunmamaktadır.

Biyosentez yönteminde kullanılmış olan defne yaprağı yll boyunca yaprak dökmeyen bir bitkidir. Ülkemizde Ege, Akdeniz, Karadeniz ve Marmara bölgelerinin kıyı ve iç kısımlarında yetiştiriciliği yapılmaktadır ve ticari olarak değere sahip olan bir bitkidir. Defne bitkisi yaprakları eterik asit bileşiğini içermektedir.

Bu çalışmada, ucuz, basit ve çevreci bir yöntem olan biyosentez yöntemiyle defne yaprağı (Laurus nobilis) özütünden yararlanılarak AgNPs nanopartikül sentezi yapılmıştır. İlk olarak AgNPs üretiminde etkili olabilecek metal tuzu/bitki özüt karışım oranı, reaksiyon süresi ve sicaklık parametreleri için optimum koşullar incelenmiştir. Daha sonra elde edilmiş olan optimum koşullarda AgNPs metalik nanopartiküller katı destek olarak modifiye silikajel üzerine kaplanmış ve yeni SiCl@AgNP nanokompoziti elde edilmiştir. Üretilmiş olan SiCl@AgNP nanokompozit yapısı UV-vis, FTIR, XRD ve SEM teknikleri kullanılarak karakterize edilmiştir. Elde edilmiş olan nanokompozit malzeme kullanılarak katyonik bir boyar madde olan metilen mavisi (MM) giderimi sürecinde adsorbent olarak kullanılabilirliği incelenmiştir. Bunun yanında adsorpsiyon sürecinde gerçekleşen mekanizmanın belirlenmesi amacıyla termodinamik parametreleri hesaplanmış ve elde edilen deneysel sonuçların Langmuir, Freundlich ve D$\mathrm{R}$ adsorpsiyon izotermlerine uygunluğu incelenmiştir.

\section{Materyal ve Metot}

$\mathrm{Bu}$ çalışmada kullanılmış olan kimyasal reaktifler Merck veya Sigma-Aldrich firmalarından temin edilmiş olup analitik saflığa sahiptirler. Çalışmada çözücü olarak deiyonize saf su kullanılmıştır. Metilen mavisi (MM) giderim çalışmalarında, ana stok çözeltisi olarak $1000 \mathrm{mg} / \mathrm{L}$ 'lik konsantrasyonlu çözelti saf su içerisinde $\mathrm{C}_{16} \mathrm{H}_{18} \mathrm{ClN}_{3} \mathrm{~S} . \mathrm{xH}_{2} \mathrm{O}(\mathrm{x}=2-3)$ (Merck) tuzunun çözündürülmesi ile elde edilmiştir. Ana stok çözeltiden günlük kullanım amaçlı olan seyreltik deney çözeltileri hazırlanmıştır. Metilen mavisi katyonik boyar maddesi giderim deneylerinde çözelti başlangıç pH'larının ayarlanması amacıyla 0,01 M sodyum hidroksit $(\mathrm{NaOH})$ ve nitrik asit $\left(\mathrm{HNO}_{3}\right)$ çözeltileri kullanılmıştır. pH metre (Jenco marka 6173) kalibrasyonunda $\mathrm{pH} 4$ ve 7 değerlerine sahip tampon çözeltilerinden yararlanılmış ve her deneysel çalışma için kör (blank) örnek kullanılmıştır.

\subsection{Defne (Laurus nobilis) yaprağı özütü hazırlanması}

Çevreci yaklaşımla Defne (Laurus nobilis) yaprağı özütü, AgNPs üretim sürecinde indirgen ajan olması yanında oluşan nanopartiküllerin kararlılaştırılması amacıylada kullanılmıştır. Çalışmada Muğla Menteşe bölgesinden Eylül ayı döneminde toplanmış olan defne bitkisinin yaprakları ilk olarak çeşme suyu ve saf su ile yıkanarak üzerinde bulunabilecek olan muhtemel kirliliklerinden arındırılarak gölgede kurutulmuştur. Kurumuş olan defne yaprakları ögütücü kullanılarak toz haline getirilmiștir.

Toz haline getirilmiş olan defne yaprağından 5 gram alınarak 20 dakika süre ile $60{ }^{\circ} \mathrm{C}$ sabit sıcaklıkta 100 mL saf suda manyetik karıştırıcı ile karıştırılarak bitki özütü hazırlanmıştır. Elde edilmiş olan açık sarı renkte çözelti soğumaya bırakıldı ve oda sıcaklığına gelmiş olan çözelti filtre kağıdı yardımıyla süzüldü. Süzüntü AgNPs nanopartikül üretiminde kullanılmak üzere buzdolabında saklandı.

\subsection{SiCl@AgNP nanokompozitinin hazırlanması}

Modifiye silikajel (SiCl) literatüre uygun olarak sentezlenmiştir [13]. Modifiye silikajel (SiCl) sentezi 
iki aşamalı olarak gerçekleştirildi. İlk aşamada ham silikajel yüzeyinin aktive edilmesi için bir cam balon içerisine 25,0 gram ham silikajel alındı ve üzerine 6 $\mathrm{mol} / \mathrm{L}, 100 \mathrm{~mL} \mathrm{HCl}$ asit ilave edildi ve 24 saat süre ile geri soğutucu altında karıştırıldı. Bu işlemin sonunda oluşan çözelti süzüldü, süzüntü distile su yardımıyla nötral olana kadar yıkandı ve $160{ }^{\circ} \mathrm{C}$ 'de 8 saat süre ile etüvde kurumaya bırakılarak aktive silikajel elde edildi. İkinci aşamada ise bir cam balona 20,0 gram aktive silikajel alındı, üzerine silanlama ajanı olan 3kloropropiltrimetoksisilan bileşiğinden $22,5 \mathrm{~mL}$ ve $200 \mathrm{~mL}$ kuru toluen ilave edildi. Elde edilen süspanse karışım geri soğutucu altında 12 saat süre ile karıştırıldı. Bu işlem sonunda oluşan karışım süzüldü ve süzüntü kısmında mevcut reaktiflerin tamamen giderilmesi amaciyla toluen, alkol ve dietil eter çözücüleri ile yıkandı, $70{ }^{\circ} \mathrm{C}^{\prime}$ de 6 süre ile etüvde kurutuldu.

AgNPs nanopartiküllerin sentezinde $\mathrm{AgNO}_{3}$ metal tuzu çözeltisinin başlangıç konsantrasyonu $10 \mathrm{mM}$ olarak alınmıştır. Nanopartikül sentezi sürecinde AgNPs üretimine etkisi olabilecek olan $\mathrm{Ag}^{+}$tuzu/defne yaprak özütü hacim oranı, sentez reaksiyon süresi ve ortam sıcaklığı parametreleri incelenmiş ve nanapartikül üretimi için optimum koşullar belirlenmiştir. İlk olarak toplam çözelti hacmi $30 \mathrm{ml}$ olacak şekilde $\mathrm{Ag}^{+}$ iyonu/defne yaprağı özütü çözeltilerinin farklı hacim oranları $(25 / 5 ; 20 / 10 ; 15 / 15 ; 10 / 20 ; 5 / 25)$ ile çalışılmış ve optimum hacim oranının 10/20 olduğu belirlenmiştir. İkinci olarak reaksiyon süresinin AgNPs metalik nanopartikül üretimi üzerine etkisinin incelenmesi için 15 ile 360 dakika reaksiyon sürelerinde çalışılmış ve optimum reaksiyon süresi olarak 180 dakikanın yeterli olduğu belirlenmiştir. Üçüncü olarak AgNPs metalik nanopartikül üretimine ortam sıcaklığının etkisi 25,50 ve $80^{\circ} \mathrm{C}$ sıcaklıklarında gerçekleştirilmiş ve optimum ortam sıcaklığı olarak $50{ }^{\circ} \mathrm{C}$ olduğu belirlenmiştir. Sentez aşamalarında gerçekleşmiş olan renk değişimi Şekil 1'de verilmiştir. AgNP nanopartiküllerinin sentezinde optimum koşulların belirlenmesi sürecinde UV-vis spektrofotometre ile 458 nm'de gözlenen AgNPs için SPR maksimum absorbans piki ile değişimler izlenmiştir.

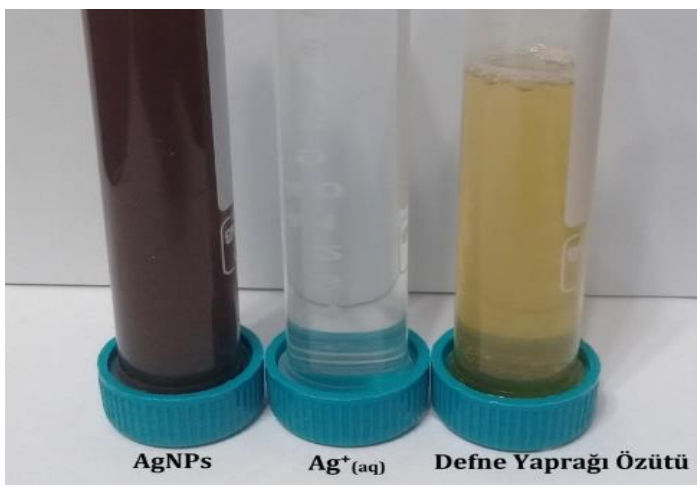

Şekil 1. Sentez sürecinde renk değişimi

AgNPs metalik nanopartikül üretimi için gerçekleştirilmiş olan deneyler sonucunda belirlenmiş olan optimum koşullardan yararlanılarak SiCl@AgNP nanokompoziti sentezi gerçekleştirildi. Nanokompozit sentezinde 0,5 g SiCl katı destek maddesi alınarak üzerine $10 \mathrm{mM} \mathrm{Ag}{ }^{+}$çözeltisiden $20 \mathrm{ml}$ ilave edildi. Karışım $50^{\circ} \mathrm{C}$ 'de su banyosu içerisinde yaklaşık 1 saat süre ile manyetik karıștırıcıda 300 rpm'de karıștırıldı. Oluşan karıșım üzerine $10 \mathrm{ml}$ damla damla defne yaprağı özütü ilave edildi ve 3 saat karıștırma işlemine devam edildi. Son oluşan çözelti karışımına 15 dakika süre ile santrifüj işlemi uygulandı ve sıvı kısım atıldıktan sonra kalan çökelek saf su ilave edilerek 2 defa santrifüj ișlemi ile yıkandı. Bu ișlemler sonucunda elde edilmiş olan kahverengi çökeleğe $80^{\circ} \mathrm{C}$ 'de etüvde 6 saatlik süreçte kurutma işlemi uygulandı.

\subsection{SiCl@AgNP nanokompoziti karakterizasyonu}

Defne yaprağı özütü kullanılarak biyosentez yöntemi ile üretilmiş olan SiCl@AgNP nanokompozit yapısı FTIR, XRD ve SEM tekniklerinden yararlanılarak karakterize edilmiştir.

\subsection{SiCl@AgNP nanokompoziti ile MM gideriminin incelenmesi}

SiCl@AgNP nanokompoziti ile MM boyar maddesinin adsorpsiyonu deneyleri kesikli (batch) yöntem ile gerçekleştirilmiştir. MM boyar maddesi adsorpsiyonunda; başlangıç çözelti pH'ı, başlangıç MM konsantrasyonu, temas süresi, adsorbent dozu ve ortam sicaklığ parametrelerinin adsorpsiyon sürecine etkileri incelenmiştir. Adsorpsiyon dengesinin oluşması sonrasında santrifüj işlemi (Nüve NF 400) uygulanarak adsorplanmadan çözeltide kalan MM miktarları, UV spektrofotometresinde (WTW photoLab 6100 VIS) $665 \mathrm{~nm}$ dalga boyunda tespit edilmiştir. Elde edilen sonuçlara göre adsorbentin denge durumunda adsorpladığ $\mathrm{MM}$ adsorpsiyon kapasitesi (Q) ve \% adsorpsiyon verimi aşağıda verilmiş olan denklemler kullanılarak hesaplanmıștır.

$$
\begin{gathered}
Q=\frac{C_{0}-C_{t}}{X_{0}} \\
\% \text { Ads.Verimi }=\frac{C_{0}-C_{t}}{C_{0}} * 100
\end{gathered}
$$

Burada;

Q: Birim kütlede adsorbent başına adsorplanmış MM boyar madde miktarı (mg/g)

$\mathrm{C}_{0}$ : Başlangıç MM konsantrasyonu (mg/L)

$\mathrm{C}_{\mathrm{t}}$ : Herhangi bir anda çözelti ortamında kalan MM konsantrasyonu (mg/L)

$\mathrm{X}_{0}$ : Adsorbent dozu (g/L)

\section{Bulgular}

\subsection{SiCl@AgNP nanokompoziti karakterizasyonu}

SiCl@AgNP nanokompozitinin FTIR spektrumu SiCl katı desteği ile birlikte Şekil 2'de verilmiştir. SiCl 
maddesi üzerine AgNP metalik nanopartiküllerinin kaplanması sonucu elde edilen SiCl@AgNP nanokompozitinin FTIR spektrumunda bariz farklılıklar gözlenmemiştir. Bu durumun nedeninin $\mathrm{SiCl}$ maddesinin üzerine kaplanmış olan AgNPs metalik nanopartikülerinin $\mathrm{SiCl}$ katı destek malzemesinden miktar olarak daha az olması sonucu oluştuğu düşünülmektedir. SiCl katı destek malzemesi ve elde edilen SiCl@AgNP nanokompozitinin IR spektrumları karşılaştırıldığında, $3466 \mathrm{~cm}^{-1}$ bölgesinde $\mathrm{SiCl}$ için gözlenmiș olan $\mathrm{O}-\mathrm{H}$ gerilme pikleri SiCl@AgNP nanokompoziti için ise $3455 \mathrm{~cm}^{-1}$ bölgesinde gözlemlenmiştir. Elde edilmiş olan spektrumlarda gözlenen alkolik ve fenolik $\mathrm{O}-\mathrm{H}$ grupları için 1635 ve $1637 \mathrm{~cm}^{-1}$ bölgelerinde gerilme piklerinin olduğu düșünülmektedir. Ayrıca 1097, 970, 799 ve $468 \mathrm{~cm}^{-1}$ bölgelerinde elde edilmiş olan piklerin SiCl@AgNP nanokompoziti karakteristik pikleri olduğu düșünülmektedir.

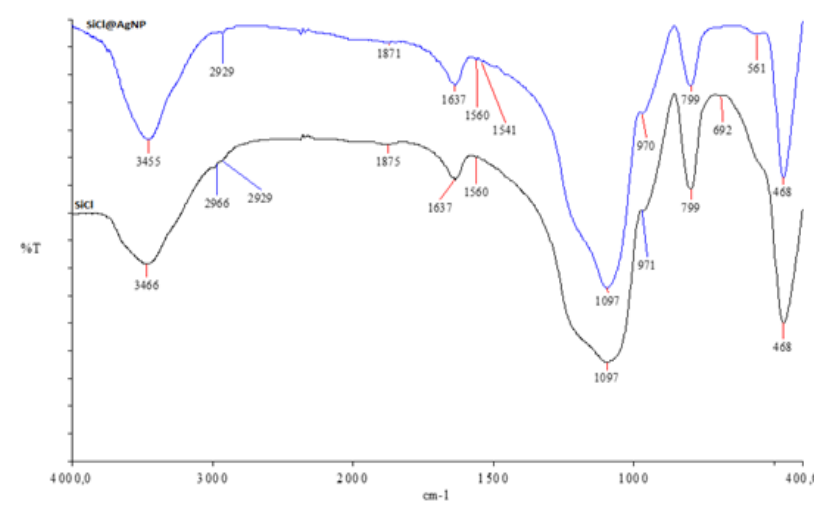

Şekil 2. FTIR spektrumları

SiCl@AgNP nanokompoziti yüzey morfolojisi değişiminin belirlenmesinde FEİ Quanta FEG 250 model Taramalı Elektron Mikroskobu (SEM) cihazı kullanılmıștır. Biyosentez yöntemi ile üretilmiş olan SiCl@AgNP nanokompoziti ve ham silikajelin SEM görüntüleri Şekil 3'de verilmiştir. Üretilmiş olan nanokompozitin SEM görüntülerinden kaplama işleminin kesin olarak gerçekleşip gerçekleşmediği konusunda bir sonuca varmak doğru olmamasına rağmen, kaplama işleminden sonra Şekil 3'de verilmiş olan SEM görüntüsünde ham silikajele göre nanokompozit yüzeyinde farklılıklar olduğu gözlenmiştir. Diğer karakterizasyon tekniklerinden elde edilmiş olan bulgular için elde edilmiş olan SEM görüntüleri bir destek oluşturmaktadır.
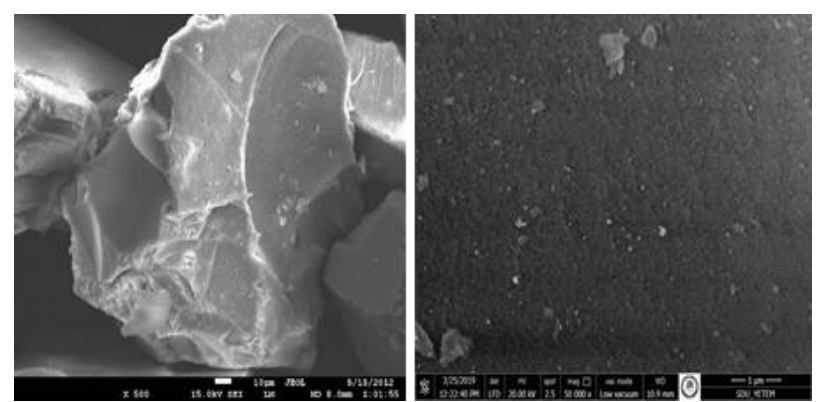

Sekil 3. Ham Silikajel (sol) ve SiCl@AgNP (sağ) SEM görüntüleri
Sentezlenmiş olan SiCl@AgNP nanokompozitinin kiristal yapının belirlenmesi amaciyla Bruker D8 Advance markalı X-Işını Difraktometresi (XRD) cihazı ile gerçekleștirilmiştir. XRD analizi sonucunda elde edilen spekrum Şekil 4'de verilmiştir. SiCl@AgNP nanokompoziti için elde edilmiş olan spektrumunda yaklaşık $38,2^{\circ}, 64,4^{\circ}$ ve $77,4^{\circ} 2 \theta$ açı değerlerinde pikler AgNP metalik nanopartiküllerinin yüzey merkezli kübik kristal yapıya sahip olduğunu göstermektedir [11,14-16].

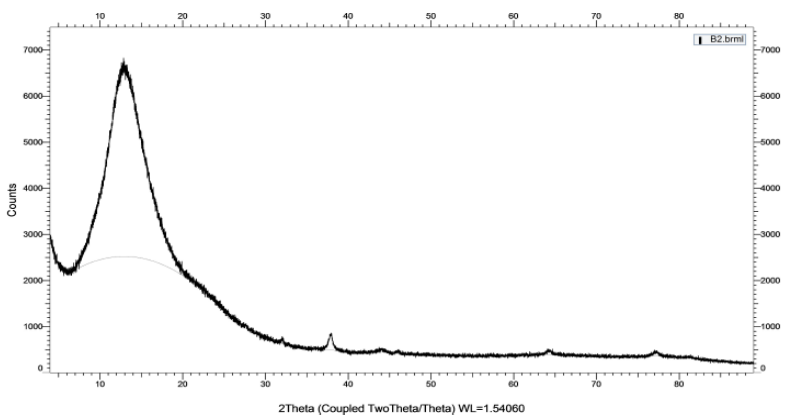

Şekil 4. XRD spektrumu

\subsection{SiCl@AgNP nanokompoziti ile MM gideriminin incelenmesi}

Çözelti başlangıç pH’ındaki değişim, adsorpsiyon süreçleri için etkili bir parametredir. SiCl@AgNP nanokompoziti için pH'a karşı adsorpsiyon kapasitesi değișimi Şekil 5'de verilmiștir. Şekil 5'de pH değerinin 6,0'dan 10,0 değerine artması ile birlikte MM giderimininde artış gösterdiği gözlenmiştir. Söz konusu adsorpsiyon kapasitesindeki artışın, pH değerinin artışı ile çözelti ortamında mevcut $\mathrm{OH}^{-}$ iyonlarının miktarının artması sonucu adsorbent yüzeyinin negatif yük yoğunluğuna sahip olması sonucu adsorbent ile çözelti ortamında bulunan katyonik MM boyar madde molekülleri arasında elektrostatik çekme kuvvetinin artmasına bağlı olabileceği düşünülmektedir. Bu nedenle SiCl@AgNP nanokompozit ile $\mathrm{MM}$ boyar maddesi gideriminde çözeltisi başlangıç pH değeri 10,0 belirlenmiştir. $\mathrm{Bu}$ pH değeri için adsorpsiyon kapasitesi ve adsorpsiyon verimi sırasıyla $5,96 \mathrm{mg} / \mathrm{g}$ ve $\% 95,4$ olarak elde edilmiştir.

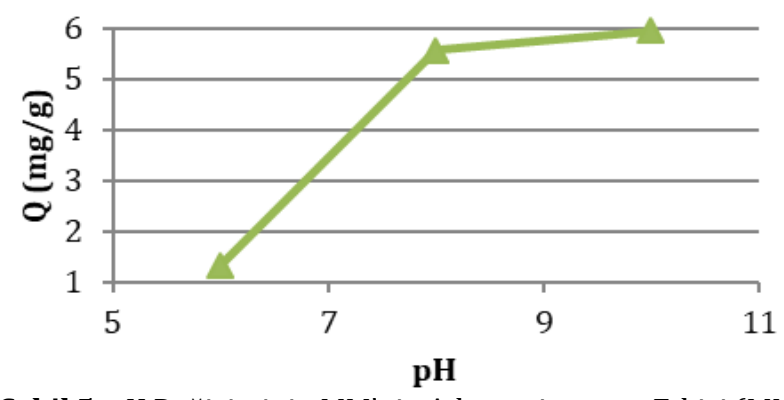

Şekil 5. pH Değişiminin MM'nin Adsorpsiyonuna Etkisi (MM konsantrasyonu: $25 \mathrm{mg} / \mathrm{L}$, temas süresi: $120 \mathrm{dk}$, adsorbent dozu: 4 g/L, ortam sıcaklığı: 25 C, çözelti hacmi: $25 \mathrm{ml}$ )

MM boyar maddesinin SiCl@AgNP nanokompoziti ile adsorpsiyonunda elde edilen temas süresi ile 
adsorpsiyon kapasitesi değişimi Şekil 6'da verilmiştir. SiCl@AgNP nanokompozit adsorbenti ile MM gideriminde temas süresi artışıyla adsorpsiyon kapasitesinin de artış gösterdiği gözlenmiştir. Şekil 6'da adsorpsiyonun dengeye ulaşmış olduğu 60 dakika optimum temas süresi olarak alınmış ve en yüksek adsorpsiyon kapasitesi olarak 5,99 mg/g değeri elde edilmiştir.

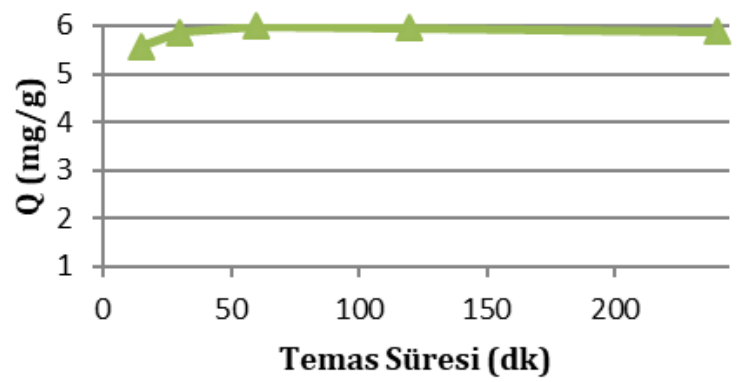

Şekil 6. Temas süresinin MM gidemine etkisi (pH: 10, MM konsantrasyonu: $25 \mathrm{mg} / \mathrm{L}$, adsorbent dozu: $4 \mathrm{~g} / \mathrm{L}$, ortam sıcaklığı: $25^{\circ} \mathrm{C}$, çözelti hacmi: $25 \mathrm{ml}$ )

SiCl@AgNP nanokompoziti ile MM boyar maddesi gideriminde, farklı adsorbent dozu oranları ile \% giderim miktarlarının değişimi Şekil 7'de verilmiştir. Adsorbent dozunun düşük olduğu çözelti ortamında yeterli miktarda nanokompozit adsorbent bulunmadığı için birim adsorbent başına adsorplanmış MM boyar madde miktarı fazla olmasına rağmen adsorplanmış madde miktarı ve \% giderim miktarı oldukça düşük olmaktadır. Adsorbent dozunun artışı ile adsorplanmış olan madde miktarının azalış göstermesi, adsorbent dozu artışı ile yüzey alanındaki tanecikler arasındaki etkileşimin artıșı sonucu meydana gelen azalmaya bağlı olduğu düşünülmektedir. Elde edilen sonuçlara göre SiCl@AgNP nanokompoziti için 4 g/L adsorbent dozu oranında en yüksek MM giderim verimi \%96,2 olarak elde edilmiştir.

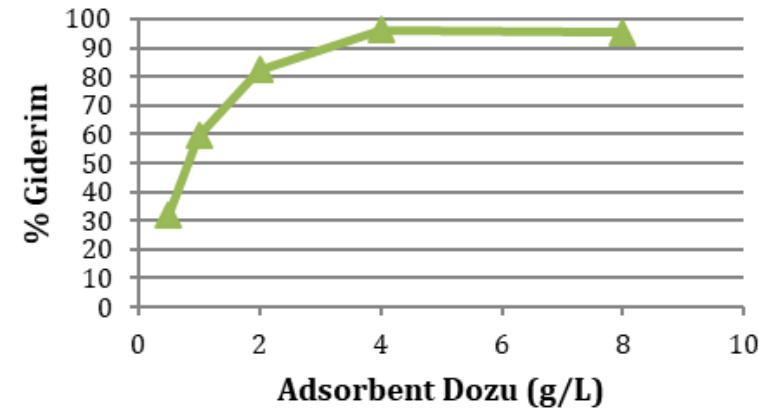

Şekil 7. Adsorbent dozu değişiminin MM giderimine etkisi (pH: 10, MM konsantrasyonu: $25 \mathrm{mg} / \mathrm{L}$, temas süresi: $60 \mathrm{dk}$, ortam sıcaklığı: $25{ }^{\circ} \mathrm{C}$, çözelti hacmi: $25 \mathrm{ml}$ )

SiCl@AgNP nanokompoziti ile MM gideriminde, farklı başlangıç MM boyar madde konsantrasyonlarına karşıllı \% giderim değerlerinin değişimi Şekil 8'de verilmiştir.SiCl@AgNP nanokompoziti adsorbenti için başlangıç MM konsantrasyonunun 25 mg/L olması durumunda \%96,2'lik giderim miktarına ulaşılmış ve sonrasında başlangıç MM boyar maddesinin konsantrasyonunun artışı ile ters orantılı olarak giderim veriminde keskin bir düşüş olduğu Şekil 8'de görülmektedir. $\mathrm{Bu}$ nedenle giderim veriminin en yüksek olduğu $25 \mathrm{mg} / \mathrm{L}$ başlangıç MM konsantrasyonu optimum değer olarak alınmıştır.

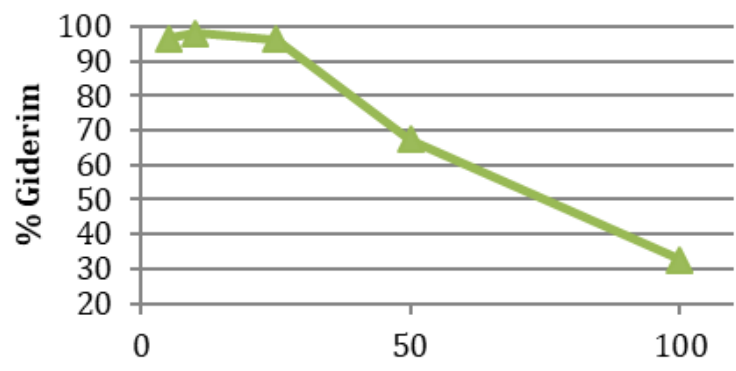

Başlangıç MM konsantrasyonu (mg/L)

Şekil 8. Başlangıç MM konsantrasyonunun MM giderimine etkisi (pH: 10, temas süresi: $60 \mathrm{dk}$, adsorbent dozu: $4 \mathrm{~g} / \mathrm{L}$, ortam sıcaklığı: $25^{\circ} \mathrm{C}$, çözelti hacmi: $25 \mathrm{ml}$ )

SiCl@AgNP nanokompoziti ile MM boyar maddesi gideriminde farklı ortam sicaklık değerleri ile adsorpsiyon kapasitesi (mg/g) değişimi Şekil 9'da verilmiștir. Şekil 9'da görüldüğü gibi SiCl@AgNP nanokompoziti için ortam sıcaklığının artışı ile birlikte adsorpsiyon kapasitesinde az miktarda artış gözlenmiştir. Şekil 9'da elde edilen verilere göre ortam sıcaklığının değişimi ile MM gideriminin çok az miktarda değişim gösterdiği belirlenmiştir. $\mathrm{Bu}$ nedenle MM giderimin ortam sıcaklığının değişimi ile az miktarda artış göstermesi endotermik karakterli bir adsorpsiyon sürecinin olduğunu göstermesine rağmen ortam sıcaklık değişimin adsorpsiyon kapasitesi değişimindeki etkisinin az olması nedeniyle enerji tasarrufu açısından optimum ortam sıcaklığının $25{ }^{\circ} \mathrm{C}$ olarak alınmasının uygun olacağ düşünülmüștür.

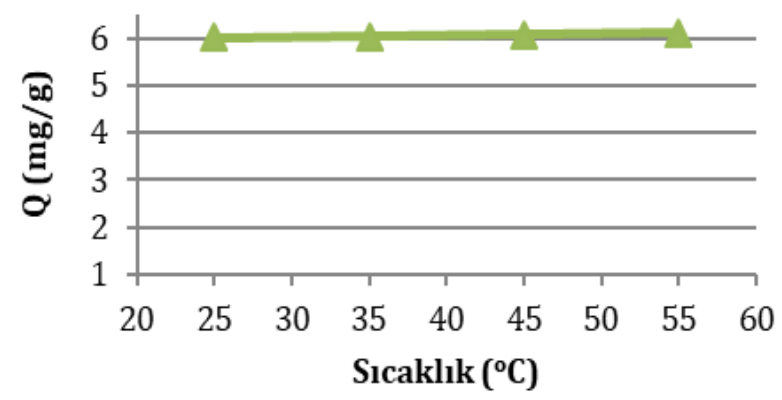

Şekil 9. Ortam sıcaklığının MM giderimine etkisi (pH: 10, MM konsantrasyonu: $25 \mathrm{mg} / \mathrm{L}$, temas süresi: $60 \mathrm{dk}$, adsorbent dozu: $4 \mathrm{~g} / \mathrm{L}$, ortam sıcaklığı: $25{ }^{\circ} \mathrm{C}$, çözelti hacmi: $25 \mathrm{ml}$ )

\subsection{SiCl@AgNP nanokompozitinin MM gideriminde termodinamik özelliklerinin incelenmesi}

SiCl@AgNP nanokompoziti ile sulu çözeltiden MM boyar maddesi gideriminde serbest enerji değişimi $(\Delta \mathrm{G})$, adsorpsiyon entalpisi $(\Delta \mathrm{H})$ ve entropi değişimi $(\Delta \mathrm{S})$ termodinamik parametreleri değerleri hesaplanmıştır. 
Termodinamikte,

$$
\Delta G=-R T \operatorname{In} K_{C}
$$

denklemi aşağıdaki gibi yazılabilir;

$$
K_{C}=e^{-\Delta G / R T}
$$

$\mathrm{K}_{\mathrm{c}}$ denge sabiti Eşitlik 5'de verilmiştir.

$$
K_{C}=\frac{C_{A}}{C_{S}}
$$

Burada; $\mathrm{C}_{\mathrm{A}}$, çözeltiden adsorbent üzerine denge durumunda adsorplanmış olan madde miktarı (mg/L) Cs, çözeltide adsorpsiyon sonrasında kalan madde miktarını ifade etmektedir.

Termodinamikte serbest enerji değişiminin, adsorpsiyon entalpisi ve entropi değişimi ile sıcaklığa bağımlılı̆̆ı;

$$
\Delta G=\Delta H-T \Delta S
$$

şeklinde verilmiştir. Buradan

$$
K_{C}=e^{-\frac{\Delta H-T \Delta S}{R T}}
$$

denklemi elde edilir. Denlemin her iki tarafının In logaritması alınması durumunda;

$$
\text { In } K_{C}=\frac{\Delta S}{R}-\frac{\Delta H}{R T}
$$

elde edilir.

Şekil 10'da SiCl@AgNP nanokompoziti ile MM boyar madde giderilmesinde 1 /T'e karşı $\ln K_{c}$ değerlerinin değişimi verilmiştir. Buradan adsorpsiyon sürecine ait $\Delta \mathrm{H}$ ve $\Delta \mathrm{S}$ termodinamik parametrelerinin değeri eșitlik 8'e göre [In Kc] vs [1/T] grafiğinin kesim noktası ve eğiminden yararlanarak hesaplanmıștır. $\Delta \mathrm{G}$ Spesifik adsorpsiyon serbest enerjisi ise Eşitlik 6'dan yararlanılarak hesaplanmıştır. Elde edilmiş olan $\Delta \mathrm{H}$, $\Delta S$ ve $\Delta G$ termodinamik parametrelerine ait sayısal değerler tablo 1 'de verilmiştir.

Pozitif değere sahip olan $\Delta \mathrm{H}$ değeri endotermik karakterli adsorpsiyon sürecini ifade etmektedir. Adsorpsiyon entalpi değerinin 2,1 - 20,9 kj/mol aralığında olması durumunda genel olarak adsorpsiyon süreci fiziksel adsorpsiyon olurken 80$200 \mathrm{~kJ} / \mathrm{mol}$ aralığında elde edilen adsorpsiyon entalpi değeri ise sürecin kimyasal adsorpsiyon olarak gerçekleștiğini göstermektedir [17-19]. Bu nedenle SiCl@AgNP nanokompoziti ile MM boyar maddesi gideriminde elde edilen $10,1 \mathrm{~kJ} / \mathrm{mol}^{\prime}$ lük adsorpsiyon entalpisi değeri nedeniyle gerçekleşen adsorpsiyon sürecinin fiziksel adsorpsiyon karakterine sahip olduğu söylenebilecektir.
Ortalama serbest enerji değişimi SiCl@AgNP nanokompoziti için $-27,04 \mathrm{~kJ} / \mathrm{mol}$ olarak elde edilmiștir. Sıcaklık artıșı ile $\Delta \mathrm{G}$ değerinin sahip olduğu daha küçük değerler nedeniyle ortam sıcaklığının yükselmesi ile adsorpsiyon prosesinin kendiliğinden yürüdügünün göstergesi olmaktadır. Kendiliğinden gerçekleşen süreçlerde düzensiz artışın oluşması nedeniyle entropi değerinde de artış gözlenmektedir. Entropinin pozitif değere sahip olması, giderim sürecinde çözelti ve katı ara yüzeyi üzerinde rastgele tutunmanın artmış olduğunu göstermektedir. Ayrıca pozitif değere sahip entropi değişiminin MM boyar maddesinin SiCl@AgNP nanokompozitine olan ilgisinin bir göstergesi olmaktadır [18-21].

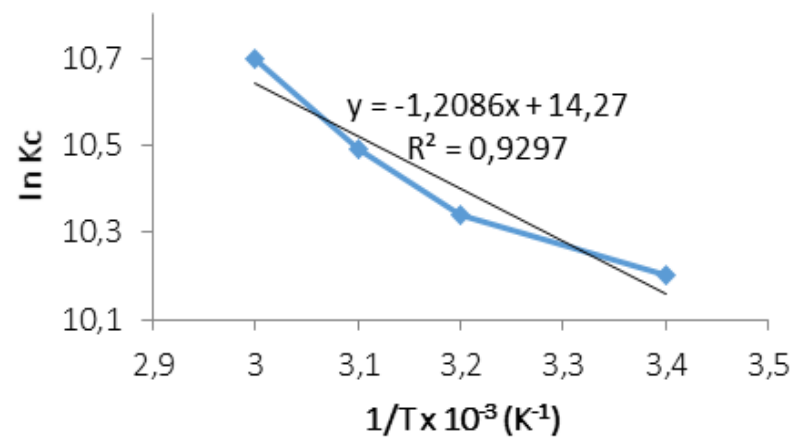

Şekil 10. MM adsorpsiyonuna ait $\left[\operatorname{InK}_{c}\right]$ vs $[1 / T]$ grafiği

Tablo 1. MM adsorpsiyonunda termodinamik parametreler

\begin{tabular}{cllll}
\hline $\boldsymbol{\Delta H}(\mathbf{k J} / \mathbf{m o l})$ & 10,1 & & & \\
$\boldsymbol{\Delta} \mathbf{S}(\mathbf{J} / \mathbf{m o l ~ K})$ & 118,6 & & & \\
$\mathbf{K}$ & 298,15 & 308,15 & 318,15 & 328,15 \\
$\boldsymbol{\Delta G} \mathbf{( k J / m o l )}$ & $-25,26$ & $-26,45$ & $-27,63$ & $-28,82$ \\
\hline
\end{tabular}

3.4. Adsorpsiyon izoterm modellerinin oluşturulması

SiCl@AgNP nanokompozit adsorbenti ile sulu çözeltiden MM boyar maddesi gideriminde belirlenmiş olan optimum koşullarda 5-100 mg/L aralığında başlangıç MM konsantrasyon değerlerinde elde edilmiş olan deneysel verilerin Langmuir, Freundlich ve D-R izotermlerine uygunluk durumu incelenmiştir.

Langmuir izoterm modeli, absorbent yüzeyinde aktif olan belli miktarda merkez üzerine tek tabakalı şekilde homojen doygun bir adsorpsiyonu kabul etmektedir. Belli miktarda adsorplanan konsantrasyonuna ulaşılması durumunda yüzeyde bir doygunluğa ulaşıldığı varsayılmaktadır. $\mathrm{Bu}$ modele göre, dinamik bir adsorpsiyon dengesine erişildiğini bir başka değişle bir dt zaman sürecinde adsorplanmış olan madde miktarı ile adsorbentin yüzeyinden ayrılan kirletici madde miktarının birbirine eşit olduğunu varsaymaktadır. Langmuir modeli $[19,22]$ aşağıda verilmiş olan eşitlik ile ifade edilmektedir;

$$
\frac{1}{Q_{e}}=\frac{1}{Q_{\max }}+\frac{1}{Q_{\max } K_{L}} \frac{1}{C_{e}}
$$


$\mathrm{C}_{\mathrm{e}}$ : Denge durumunda çözelti ortamında kalan adsorplanmamış MM konsantrasyonunu (mg/L) ifade etmektedir.

$Q_{e}$ : Denge durumunda, birim adsorbent kütlesinin adsorplamış olduğu MM miktarını (mg/g), $\mathrm{Q}_{\max }$ (mg/g) ve $\mathrm{K}_{\mathrm{L}}(\mathrm{L} / \mathrm{mg})$ değerleri kapasite ve enerji ile bağlantılı Langmuir sabiti değerlerini ifade etmektedir. Elde edilen bu değerlerin sabitleri tablo 2'de verilmiştir. SiCl@AgNP nanokompoziti ile MM boyar maddesinin gideriminde elde edilen Langmuir izotermi grafiği Șekil 11'de verilmiștir.

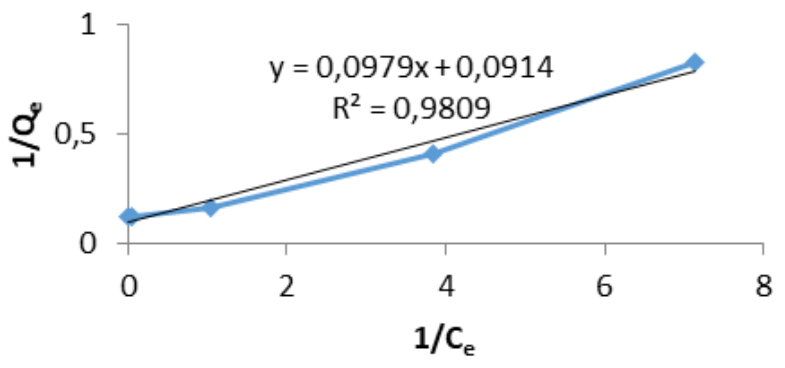

Şekil 11. Langmuir İzoterm modeli

İzotermal adsorpsiyonu ifade eden Freundlich izoterm modeli heterojen yüzey enerjileri açısından özel bir durumu göstermektedir. Genel anlamda, Freundlich izoterm modeline göre adsorplanmış olan madde miktarının artıșı ile adsorpsiyon dengesinin olușması durumunda adsorplanmıș madde miktarlarının artış gösterdiği heterojen yüzeylerde gerçekleşen daha gerçekçi bir adsorpsiyonu temsil eden bir modeldir. Freundlich izoterm modeli $[19,23]$ aşağıda verilmiş olan eşitlik ile ifade edilmektedir;

$$
\log q_{e}=\log K_{F}+\frac{1}{n} \log C_{e}
$$

Yukarıdaki eşitlikte, $\mathrm{q}_{\mathrm{e}}$ ve $\mathrm{C}_{\mathrm{e}}$ değerleri Langmuir izoterm modelindeki qe ve C 'ye eşdeğerdir. $\mathrm{K}_{\mathrm{F}}(\mathrm{mg} / \mathrm{g})$ ise kapasite ile bağlantili Freundlich izoterm sabitini ifade etmektedir, heterojenite faktörü olan $1 / \mathrm{n}$ değeri 0 ile 1 aralığında bir değere sahiptir. Heterojen yüzeyler için heterojenliğin artışı ile birlikte $1 / \mathrm{n}$ değeri de sıfıra yaklaşmaktadır. Tablo 2'de hesaplanmış olan bu sabitlerin değerleri verilmiştir. SiCl@AgNP nanokompoziti ile MM boyar maddesi giderimine ait elde edilen Freundlich izoterm modeli grafiği Şekil 12'de verilmiştir.

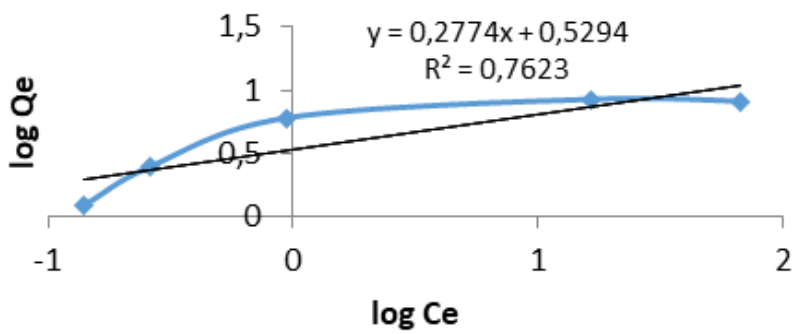

Şekil 12. Freundlich izoterm modeli

Adsorplanmış sıvı faz buhar basıncının aynı sıcaklığa sahip saf sıvı faz buhar basıncına eşit olduğunu, sistemin dengeye ulaşması durumunda 1 mol maddenin buhar fazından adsorplanan faza tersinir bir şekilde taşınması durumunda maksimum işin $E$ olarak tanımlanmış olan adsorpsiyon potansiyeli Polonyi izotermini esas almaktadır. DubininRadushkevich (D-R) izoterm modelinde adsorbent adsorpsiyon potansiyelinin mikrogözenek hacmi ile değişiminin Gauss dağılımına benzediğini ileri sürülerek, buhar fazından adsorpsiyonlarda $\varepsilon=$ $\mathrm{RT} \ln \left[\mathrm{P}_{\mathrm{o}} / \mathrm{P}\right]$, çözelti fazından adsorpsiyonlarda ise $\varepsilon=$ $\mathrm{RT} \ln \left[1+\left(1 / \mathrm{C}_{\mathrm{e}}\right)\right]$ olarak alınır. $\mathrm{X}_{\mathrm{m}}$ değeri maksimum iyon değișim kapasitesini ve $\beta$ değeri ise adsorplanmıș olan kirleticiye ait özel bir sabit değer olmak üzere D$\mathrm{R}$ adsorpsiyon izoterm modeli $[17,24]$ için aşağıdaki denklem verilmiştir.

$C_{a d s}=X_{m} \exp \left(-\beta \varepsilon^{2}\right)$ veya $\ln C_{a d s}=\ln X_{m}-\beta . \varepsilon^{2}$

D-R adsorpsiyon izoterm modeli incelendiğinde adsorpsiyon bulguları kullanılarak SiCl@AgNP nanokompozit adsorbenti için Şekil 13'de [E²] vs [lnC $\left.\mathrm{l}_{\text {ads }}\right]$ değişim grafiği verilmiştir. Elde edilen grafiğin eğim ve kesim noktasından yararlanılarak Xm ve $\beta$ değerleri hesaplanmış ve tablo 2'de verilmiştir. Hesaplanmış olan $\beta$ değerinin kullanılmasıyla E adsorpsiyon enerjisi; $\quad E=1 /(-2 \beta)^{1 / 2}$ denklemi kullanılarak hesaplanmıștır.

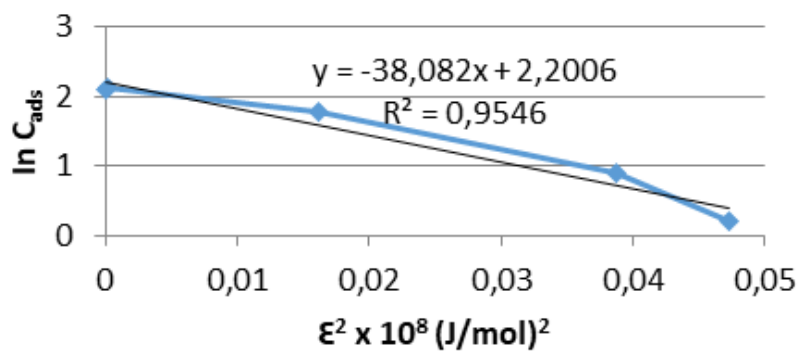

Şekil 13. D-R izoterm modeli

Tablo 2. Adsorpsiyon izoterm sabitleri

\begin{tabular}{ccc}
\hline & Langmuir \\
$\mathrm{Q}_{\max }(\mathrm{mg} / \mathrm{g})$ & $\mathrm{K}_{\mathrm{L}}(\mathrm{L} / \mathrm{mg})$ & $\mathrm{R}^{2}$ \\
10,94 & 0,93 & 0,981 \\
\hline \multicolumn{3}{c}{ Freundlich } \\
$\mathrm{K}_{\mathrm{f}}(\mathrm{mg} / \mathrm{g})$ & $1 / \mathrm{n}$ \\
3,38 & 0,28 & $\mathrm{R}^{2}$ \\
\hline \multicolumn{3}{c}{ Dubinin-Radushkevich (D-R) } \\
$\mathrm{X}_{\mathrm{m}}(\mathrm{mg} / \mathrm{g})$ & $\mathrm{E}(\mathrm{kJ} / \mathrm{mol})$ & $\mathrm{R}^{2}$ \\
9,03 & 1,15 & 0,955 \\
\hline
\end{tabular}

SiCl@AgNP nanokompoziti ile sulu çözeltiden MM giderimi sürecinin Langmuir, Freundlich ve D-R izoterm modellerine uygunluğu incelenmiștir. Tablo 2'de verilmiş olan $\mathrm{R}^{2}$ değerlerine bakıldığında adsorpsiyon sürecinin Langmuir izoterm modeli için elde edilen 0,981 değeri nedeniyle diğer izoterm modellerine göre Lagmuir izoterm modeli ile uyum içerisinde olduğu belirlenmiştir. $\mathrm{Bu}$ nedenle SiCl@AgNP nanokompozit adsorbenti ile MM boyar madde gideriminde Langmuir izotermine uygunluk göstermesi, nanokompozit yüzeyinde mevcut belli sayıdaki aktif merkez tarafından tek tabakalı dinamik 
bir adsorpsiyon prosesinin oluştuğu ve adsorbent yüzeyinin doygunluğa ulaştığı sonucuna varllabilmektedir.

\subsection{SiCl@AgNP ile MM adsorpsiyonunun literatür karşılaştırması}

Literatür çalışmalarında MM boyar maddesi giderimi sürecinde kullanılan malzemelerin katalitik aktivite [5,7,8,10,11,12] ve adsorban [2,25-30] özelliklerinin incelenmesine yönelik çalışmalar bulunmaktadır. Çalışmamızda MM giderimi için adsorpsiyon yöntemi kullanılmış ve benzer malzemeler ile yapılmış olan çalışmalarda elde edilen MM boyar maddesi için adsorplama kapasitesine ilişkin literatür verileri tablo 3'de verilmiştir. Tabloda verilen adsorbentlerin MM adsorplama kapasiteleri ( $\mathrm{Q}_{\max }, \mathrm{mg} / \mathrm{g}$ ) karşılaştırıldığında SiCl@AgNP adsorbenti için elde edilen adsorplama kapasitesine göre daha yüksek değerler olmasına rağmen çalışmada elde edilmiş verinin anlamlı olduğu düşünülmektedir.

Tablo 3. MM gideriminde kullanılan bazı adsorbentler için maksimum adsorpsiyon kapasitesi (Qmax, mg/g) karşılaştırılması

\begin{tabular}{ccc}
\hline Adsorbent & $\mathbf{Q}_{\max }(\mathbf{m g} / \mathbf{g})$ & Kaynak \\
\hline $\mathrm{Ag}$ NPs-AC & 34,5 & {$[25]$} \\
\hline $\mathrm{AgNPs}-\mathrm{AC}$ & 172,2 & {$[26]$} \\
\hline $\mathrm{Ag} / \mathrm{SiO}_{2}-6$ & 37,0 & {$[27]$} \\
\hline Silika kserojel & 51,9 & {$[28]$} \\
\hline $\mathrm{AgNPs}$ & 45,25 & {$[29]$} \\
\hline AgNPs-AC & 75,20 & {$[30]$} \\
\hline SiCl@AgNP & 6,11 & Bu çalıșma \\
\hline
\end{tabular}

\section{Tartışma ve Sonuç}

Bu çalışmada, ilk olarak defne yaprağı özütü kullanılarak biyosentez yöntemi ile AgNPs metalik nanopartikül üretimi için optimum koşullar belirlenmiştir. Elde edilmiş olan optimum koşullardan yararlanılarak metalik nanopartiküllerin $\mathrm{SiCl}$ katı desteği üzerine kaplanması sonucunda SiCl@AgNP nanokompoziti elde edilmiştir. Elde edilmiş olan SiCl@AgNP nanokompozitinin yapısı FTIR, XRD, SEM teknikleri kullanılarak karakterize edilmiştir. Daha sonra elde edilmiş olan nanokompozitin adsorptif özelliklerinin belirlenebilmesi için katyonik bir boyar madde olan MM adsorpsiyonu incelenmiştir. Giderim deneylerinde nanokompozit üzerine adsorpsiyona etki edebilecek olan çözelti başlangıç $\mathrm{pH}^{\prime}$ ı, başlangıç MM konsantrasyonu, temas süresi, adsorbent dozu ve ortam sicaklı̆̆ parametrelerinin etkisi incelenmiştir. SiCl@AgNP nanokompoziti ile MM boyar madde gideriminde elde edilen optimum koşullar; $\mathrm{pH}$ 10; başlangıç MM konsantrasyonu $25 \mathrm{mg} / \mathrm{L}$; temas süresi 60 dakika; adsorbent dozu 4 g/L ve ortam sıcaklığı 25 ${ }^{\circ} \mathrm{C}$ olarak elde edilmiştir.

SiCl@AgNP nanokompozitinin deneysel sonuçlarının Langmuir, D-R ve Freundlich ve izoterm modellerine uygunluk durumu incelenmiş ve gerçekleşen adsorpsiyon sürecinin Langmuir izoterm modeli ile uyum içerisinde olduğu belirlenmiştir. SiCl@AgNP nanokompoziti için deneysel olarak adsorpsiyon kapasitesi 6,11 mg/g elde edilmişken Langmuir izotermine göre $10,94 \mathrm{mg} / \mathrm{g}$ olarak hesaplanmıştır. MM gideriminde SiCl@AgNP nanokompozit adsorbenti için $\Delta \mathrm{H}, \Delta \mathrm{S}$ ve $\Delta \mathrm{G}$ termodinamik parametreleri hesaplanmış ve elde edilen sonuçlara göre gerçekleșen adsorpsiyon sürecinin endotermik karakterli olduğu ve kendiliğinden gerçekleştiği sonucuna varılmıştır.

Elde edilen sonuçlara göre SiCl@AgNP nanokompozitinin $\mathrm{MM}$ boyar madde gideriminde etkin olduğu belirlenmiş ve sentezlenmiş olan nanokompozitin diğer katyonik boyar maddelerin gideriminde bir adsorbent olarak kullanılabileceği düşünülmektedir.

\section{Teşekkür}

$\mathrm{Bu}$ Makale Burcu Akyol ORAL'ın Yüksek Lisans tezinden hazırlanmıştır.

\section{Etik Beyanı}

Bu çalışmada, "Yükseköğretim Kurumları Bilimsel Araștırma ve Yayın Etiği Yönergesi" kapsamında uyulması gerekli tüm kurallara uyulduğunu, bahsi geçen yönergenin "Bilimsel Araştırma ve Yayın Etiğine Aykırı Eylemler" başlığı altında belirtilen eylemlerden hiçbirinin gerçekleştirilmediğini taahhüt ederiz.

\section{Kaynakça}

[1] Kadığlu, S. 2016. Metal bezeli silika partiküllerinin yarı-biyosentezle üretimi, yapısal analizi ve özelliklerinin incelenmesi. Muğla Sitkı Koçman Üniversitesi, Fen Bilimleri Enstitüsü, Doktora Tezi, 226s, Muğla.

[2] Khajeh, M., Kaykhaii, M., Sharafi, A. 2013. Application of PSO-artificial neural network and response surface methodology for removal of methylene blue using silvernanoparticles from water samples. Journal of Industrial and Engineering Chemistry, 5, 1624-1630.

[3] Salem, M. A., Elsharkawy, R. G., Hablas, M. F. 2012. Adsorption of brilliant green dye by polyaniline/silver nanocomposite: Kinetic, equilibrium and thermodynamic studies. European Polymer Journal, 75, 577-590.

[4] Ghaedi, M., Sadeghian, B., Pebdani, A. A., Sahraei, R., Daneshfar, A., Duran, C. 2012. Kinetics, thermodynamics and equilibrium evaluation of direct yellow 12 removal by adsorption onto silver nanoparticles loaded activated carbon. Chemical Engineering Journal, 187, 133- 141.

[5] Vilchis-Nestor, A. R., Trujillo-Reyes, J., Colı́nMolina, J. A., Sa'nchez-Mendieta, V., Avalos-Borja, M. 2014. Biogenic silver nanoparticles on carbonaceous material from sewage sludge for 
degradation of methylene blue in aqueous solution. International Journal of Environmental Science and Technology, 11, 977-986.

[6] Satapathy, M. K., Banerjee, P., Das, P. 2015. Plantmediated synhesis of silver-nanocomposite as novel effective azo dye adsorbent. Applied Nanoscience, 5(1), 1-9.

[7] Devi, T. A., Ananthi, N., Amaladhas, T. P. 2016. Photobiological synthesis of noble metal nanoparticles using Hydrocotyle asiatica and application as catalyst for the photodegradation of cationic dyes. Journal of Nanostructure in Chemistry, 6, 75-92.

[8] Saha, J., Begum, A., Mukherjee, A., Kumar, S. 2017. A novel green synthesis of silver nanoparticles and their catalytic action in reduction of Methylene Blue dye. Sustainable Environment Research, 27, 245-250.

[9] Nguyen, T. D., Dang, C. H., Mai, D. T. 2018. Biosynthesized AgNP capped on novel nanocomposite 2-hydroxypropyl$\beta$ cyclodextrin/alginate as a catalyst for degradation of pollutants. Carbohydrate Polymers, 197, 29-37.

[10] Joseph, S., Mathew, B. 2015. Microwave-assisted green synthesis of silver nanoparticles and the study on catalytic activity in the degradation of dyes. Journal of Molecular Liquids, 204, 184-191.

[11] Edison, T. N. J. I., Atchudan, R., Kamal, C., Lee, Y. R. 2016. Caulerpa racemosa: a marine green alga for eco-friendly synthesis of silver nanoparticles and its catalytic degradation of methylene blue. Bioprocess and Biosystems Engineering, 39, 1401-1408.

[12] Bordbar, M. 2017. Biosynthesis of Ag/almond shell nanocomposite as a cost-effective and efficient catalyst for degradation of 4-nitrophenol and organic dyes. Royal Society of Chemistry, 7, 180-189.

[13] Sadeghi, S., Sheikhzadeh, E. 2009. Solid phase extraction using silica gel modified with murexide for preconcentration of uranium (VI) ions from water samples. Journal of Hazardous Material, 163, 861-868.

[14] Sreekanth, T. V. M., Pandurangan, M., Jung, M. J., Lee, Y. R., Eom, I. Y. 2016. Eco-friendly decoration of graphene oxide with green synthesized silver nanoparticles: cytotoxic activity. Research on Chemical Intermediates, 42, 5665-5676.

[15] Ding, J., Bu, Y., Ou, M., Yu, Y., Zhong, Q., Fan, M. 2017. Facile decoration of carbon fibers with $\mathrm{Ag}$ nanoparticles for adsorption and photocatalytic reduction of $\mathrm{CO}_{2}$. Applied Catalysis B: Environmental, 202, 314-325.

[16] Liu, X., Liang, M., Liu, M., Su, R., Wang, M., Qi, W., He, Z. 2016. Highly efficient catalysis of azo dyes using recyclable silver nanoparticles immobilized on Tannic acid-grafted eggshell membrane. Nanoscale Research Letters, 11(440), 1-9.

[17] Liu, Y., Liu, Y .J. 2008. Biosorption isotherms, kinetics and thermodynamics. Separation and Purification Technology, 61, 229-242.

[18] Gök, C. 2010. Uranyum ve Toryumun Adsorpsiyonu için Aljinat Biyopolimerlerinin Hazırlanması ve Çeşitli Uygulama Alanlarının İncelenmesi. Ege Üniversitesi, Fen Bilimleri Enstitüsü, Doktora Tezi, 136s, İzmir.

[19] Kırkan, B. 2012. Yatağan Termik Santrali Kül Dağındaki Toryumun Kül ve Topraktaki Davranışının ve Yeraltı Sularına Geçişinin İncelenmesi, Katı Faz Ekstraksiyonu ile Deriştirilmesi. Muğla Sıtkı Koçman Üniversitesi, Fen Bilimleri Enstitüsü, Doktora Tezi, 204s, Muğla.

[20] Uğurlu, M. 2009. Adsorption of a textile dye onto activated sepiolite. Microporous and Mesoporous Materials, 119, 276-283.

[21] Uğurlu, M., Karaoğlu, M. H. 2011. Adsorption of ammonium from an aqueous solution by fly ash and sepiolite: Isotherm, kinetic and thermodynamic analysis. Microporous and Mesoporous Materials, 139, 173-178.

[22] Langmuir, I. 1918. The adsorption of gases on plane surfaces of glass, mica and platinium. Journal of American Chemical Society, 40, 13611403.

[23] Freundlich, H. M. F. 1906. Über die adsorption in lösungen. Zeitschrift für Physikalische Chemie (Leipzig), 57A, 385-470.

[24] Dubinin, M. M., Zaverina, E. D., Radushkevich, L. V. 1947. Sorption and structure of active carbons. I. Adsorption of organic vapors. Zhurnal Fizicheskoi Khimii, 21, 1351-1362.

[25] Ghaedi, M., Heidarpour, S., Kokhdan, S. N., Sahraie, R., Daneshfar, A., Brazesh, B., 2012. Comparison of silver and palladium nanoparticles loaded on activated carbon for efficient removal of Methylene blue: Kinetic and isotherm study of removal process. Powder Technology, 228, 18-25.

[26] Van, H. T., Nguyen, T. M. P., Thao, V. T., Vu, X. H., Nguyen, T. V., Nguyen, L. H., 2018. Applying activated carbon derived from coconut shell loaded by silver nanoparticles to remove methylene blue in aqueous solution. Water Air Soil Pollution, 229(393), 1-14.

[27] Hu, M., Yan, X., Hu, X., Feng, R., Zhou, M. 2019. Synthesis of silver decorated silica nanoparticles with rough surfaces as adsorbent and catalyst for methylene blue removal. Journal of Sol-Gel Science and Technology, 89, 754-763. 
[28] Guzel Kaya, G., Yilmaz, E., Deveci, H. 2019. A novel silica xerogel synthesized from volcanic tuff as an adsorbent for high-efficient removal of methylene blue: Parameter optimization using Taguchi experimental design. Journal of Chemical Technology \& Biotechnology, 94, 2729-2737.

[29] Jabbari, R., Ghasemi, N. 2021. Investigating methylene blue dye adsorption isotherms using silver nano particles provided by aqueous extract of tragopogon buphthalmoides. Chemical Methodologies, 5, 21-29.

[30] Ghaedi, M., Roosta, M. A., Ghaedi, M., Ostovan, A., Tyagi, I., Agarwal, S., Gupta, V. K. 2018. Removal of methylene blue by silver nanoparticles loaded on activated carbon by an ultrasound-assisted device: optimization by experimental design methodology. Research on Chemical Intermediates, 44, 2929-2950. 